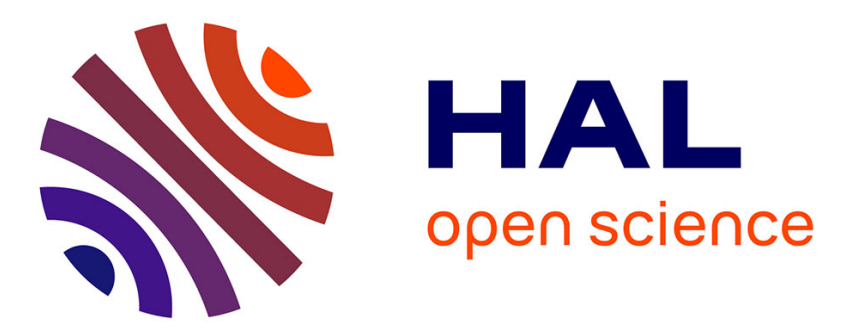

\title{
Cobalt-based superalloy layers deposited on X38CrMoV5 steel base metal by explosion cladding process
}

S. Ettaqi, Laurent Langlois, Régis Bigot

\section{- To cite this version:}

S. Ettaqi, Laurent Langlois, Régis Bigot. Cobalt-based superalloy layers deposited on X38CrMoV5 steel base metal by explosion cladding process. Surface and Coatings Technology, 2008, 202, p. 33063315. 10.1016/j.surfcoat.2007.12.008 . hal-00733915

\section{HAL Id: hal-00733915 \\ https://hal.science/hal-00733915}

Submitted on 20 Sep 2012

HAL is a multi-disciplinary open access archive for the deposit and dissemination of scientific research documents, whether they are published or not. The documents may come from teaching and research institutions in France or abroad, or from public or private research centers.
L'archive ouverte pluridisciplinaire HAL, est destinée au dépôt et à la diffusion de documents scientifiques de niveau recherche, publiés ou non, émanant des établissements d'enseignement et de recherche français ou étrangers, des laboratoires publics ou privés. 


\title{
Cobalt Based Superalloy layers deposited on X38CrMoV5 steel base metal by explosion cladding process.
}

\author{
S. Ettaqi ${ }^{a}$, L. Langlois ${ }^{b *}$, R. Bigot ${ }^{b}$. \\ ${ }^{a}$ Département Matériaux et Procédés, ENSAM de Meknès, Université Moulay Ismail, Marjane II, \\ Meknès Ismailia, BP 4024 Béni M'Hamed, Maroc. \\ ${ }^{\mathrm{b}}$ Laboratoire de Génie Industriel et de Production Mécanique, ENSAM CER de Metz, 4 rue Augustin \\ Fresnel, 57078 Metz Cedex 3, France
}

\begin{abstract}
A grade 25 cobalt-based superalloy in the form of a sheet $5 \mathrm{~mm}$ in thickness and a steel substrate of type $\mathrm{X} 38 \mathrm{CrMoV} 5$ are joined by explosion cladding. The macrostructure and microstructure of the interface and of the co-based superalloy layers are studied. The interface presents the form of wavelets with a period of $1000 \mu \mathrm{m}$ and an amplitude of $250 \mu \mathrm{m}$. The superalloy grains are deformed during the cladding process with several slip systems appearing. Near to the interface, the superalloy grains elongate and tend to follow the geometry of the interface. Observation with a scanning electron microscope (SEM) reveals zones of localised fusion at the interface. The EDS analysis shows that these fusion zones are the result of mixing between the base and cladding plates. Radiocrystallographic analysis by X-ray diffraction reveals the presence of the f.c.c cobalt in the cobalt-based superalloy layer. Thus cobalt retains its crystallographic structure (f.c.c) after cladding process. Hardness is evaluated with reference to microstructure. Near the interface, the hardness of the superalloy is of the order of $600 \mathrm{HV}_{1 \mathrm{~kg}}$. In the remainder of the thickness, hardness is of the order of 500 $\mathrm{HV}_{1 \mathrm{~kg}}$, being greater than that of the unplated superalloy $\left(270 \mathrm{HV}_{1 \mathrm{~kg}}\right)$. The track obtained by an indentation test at the interface under a load of $100 \mathrm{~kg}$ exhibits no cracking. This tends to prove the good metallurgical bond at the interface.
\end{abstract}

Keywords: Explosion cladding process, Co-based superalloy, Interface, Microstructure

*Corresponding autor. Phone: +33.3.87.37.54.30; fax: +33.3.87.37.54.70.

E-mail address: laurent.langlois@ensam.metz.fr (L.Langlois) 


\section{Introduction:}

The increasing competition in technological performance encourages further research relating high performance products with reduced manufacturing costs. These aims sometimes call existing knowledge into question and encourage research into new materials and/or new processes. In many industrial applications such as forging, tools are subjected to very severe thermal, mechanical and tribological stresses. Interaction between these factors generally results in damage to the tools. Several combinations of processes and materials are used to reduce the various damage modes. Conventional processes for surface properties modification are the subjects of widespread studies. Various research projects combining cobalt-based superalloys and Plasma Transferred Arc (PTA) [1-4] or Tungsten Inert Gas (TIG) [5-6] processes are under way. The coatings obtained by these methods exhibit good wear resistance. In recent years, other non-conventional surface modification processes have been developed, such as the laser surfacing process in order to enhance the wear and corrosion resistance of materials surface [7]. Surface alloys developed by this technique are generally cobalt-based alloys [8,9] or nitrides [10]. Recently, several theoretical and experimental research projects have been carried out into explosion cladding [11-15]. Explosive cladding is a solid-state process in which controlled explosion joins two or more identical or different materials under high pressure. This technique uses the energy produced by an explosion to accelerate a flyer plate across a distance (Stand-off idstance as shown in figure 1) into contact with the base plate. The high localized temperature and pressure due to the dynamics of the process, and the localised plastic flow at the welded interface allow strong interface bond. Contrary to arc welding, Plasma Transferred Arc or laser coating, explosion cladding does not exhibit dilution between the base metal and the cladding layer. This feature allows a good control of the coating chemical composition. As explosive cladding is a solid-state process it is possible to join metals that may exhibit hot cracking sensitivity. The coating compactness is 
$100 \%$. The high speed of the process avoids the formation of brittle intermetallic components at the bonding interface. Many combinations of metal alloy can be joined together. Hokamoto et al. [16] have succeeded in cladding aluminium on zirconium ceramic. The main restrictive feature of explosion cladding is the only possibility to join flat sheets, tubes or shapes with low curvature. The metals must have enough impact resistance and ductility. Another disadvantage is the low productivity of the process.

The parameters of the explosion cladding process, the mechanical properties of the obtained cladded sheet and the relation between them are recent areas under the research $[17,18]$. Research shows that the mechanical properties can be strongly linked to the microstructure and the phases formed by local fusion at the interface $[19,20]$.

This paper presents the investigations of cobalt based superalloy cladding on steel by explosive cladding. These investigations focus on the interface between the two materials and the superalloy coating. Macrostructure and microstructure are studied in detail. Hardness and indentation tests at the interface are presented.

\section{Experimental details:}

The experimental details are presented in figure 2. A Cobalt based superalloy sheet and a steel sheet of dimension $(800 \mathrm{~mm} \times 800 \mathrm{~mm} \times 6 \mathrm{~mm})$ and $(800 \mathrm{~mm} \times 800 \mathrm{~mm} \times 80 \mathrm{~mm})$ respectively are joined by explosive cladding. The chemical composition of the two materials is given in table 1 . Two kinds of sample are mechanically cut from the bi-material sheet. The first one, of dimension $(15 \mathrm{~mm} \times 15 \mathrm{~mm} \times 10 \mathrm{~mm})$, is used for the observation of the interface morphology and X-ray analysis of the co-based alloy close to the interface and at the surface of the sample (see figure 2). The second one, of dimension $(40 \mathrm{~mm} \times 10 \mathrm{~mm} \times 10 \mathrm{~mm})$ is used for the micrographic observation of the microstructure of the co-based layer and the steel close to the interface and at the surface of the sample. This kind of sample is also used for the micro hardness analysis of the coating. 
In order to study the interface morphology, two steps are required. The first step involves mechanically removing a large proportion of the $\mathrm{X} 38 \mathrm{CrMoV} 5$ steel used as base metal. The second step involves etching with high concentrate Fry's reagent for a few days to remove the remaining steel. X-ray diffraction analysis of the Co-based alloy at the surface and at the interface is proceeded with a Seifert 3003 PTS diffractometer with a linear detector using an iron cathode $(\lambda=1.93604 \AA$. $)$.

The microstructure of co-based alloy and the steel is investigated by optical microscopy and scanning electron microscope. In order to observe the steel microstructure close to the interface, samples are first etched by Nital 3\% reagent. The microstructure of the co-based alloy close to the interface and at the surface is etched by Fry's reagent $(90 \mathrm{~g} \mathrm{CuCl}, 120 \mathrm{ml}$ $\mathrm{HCl}, 100 \mathrm{ml} \mathrm{H}_{2} \mathrm{O}$ ). Variation in chemical composition at the interface is analysed by EDS. Hardness is measured on the cross-sections immediately after polishing. Measurements are performed under a load of $1 \mathrm{~kg}$ with a loading time of $10 \mathrm{~s}$. Testing of the mechanical strength of the interface is carried out by indentation tests under a load of $100 \mathrm{~kg}$.

\section{Results and discussion}

\section{1. Macrostructure and microstructure}

A macrograph of the interface after total removal of the steel and a micrograph of a cross section of the cladded sheet are given in figure $3 \mathrm{a}$ and $3 \mathrm{~b}$ respectively. The interface exhibits a wavy morphology. The observed waves are periodic (period $\mathrm{T} \sim 1000 \mu \mathrm{m}$ ) with relatively constant amplitude $(\mathrm{a} \sim 250 \mu \mathrm{m})$. This feature commonly observed in explosive cladding is due to periodic disturbances of the material and variations in the velocity distribution during the process [24]. The interface resistance is not directly related to the wave morphology. Interface strength higher than the one of the weaker material is obtained however there is a wavy or straight interface [15]. 
Figures 4 show the microstructure of the superalloy before cladding. Chemical etching reveals a banded structure, corresponding to the twinned crystals formed during rolling of the superalloy. The optical micrograph (Figure $4 \mathrm{~b}$ and $4 \mathrm{c}$ ) shows the structure of these unidirectional bands in detail. The optical micrograph of the figure 5 shows the microstructure of the Co-based superalloy after cladding. This microstructure is formed of equiaxial grains with unidirectional bands and in several directions.

Figure 6e shows two types of local fusion at the interface. These two zones are the result of rapid local fusion/solidification phenomena. The structure of the first zone of local fusion is very fine and homogeneous (HOLMZ1). The second type of local fusion zone is heterogeneous (HELMZ2). Acarer et al. [15] suggested that this local melting is due to the transformation of kinetic energy into heat energy during impact. The difference between HOLMZ1 and HELMZ2 can be due to a difference of cooling rate or a difference between the thermo mechanical conditions of their formation. In the study of Aluminium alloy explosive welding on steel, Li et al. [17], shows zones at the interface where superplastic deformation takes place. In HOLMZ2, the heterogeneity can be due to a mixture of superplatic flow/melting or due to a very high cooling rate preventing diffusion from complete homogenization of the zone.

At the interface, on the Co-based superalloy side, a light-coloured zone (ZE1) (see Figure 6c), of low thickness corresponds to a highly work-hardened zone where the grains are greatly elongated in the explosive welding direction and follow the wavy morphology (Figure 6d). A thin layer (less than $10 \mu \mathrm{m}$ thick) of $\mathrm{ZE} 1$, at the interface, has very thin grains. During formation of the explosive cladding bonding, the grains of the face superalloy involved in the formation of the interface are very significantly deformed due to the pressure and the heat exerted by the explosion and by the impact of the sheet on the steel base. The higher this deformation, the higher are the temperatures generated at the surface and at the interface. 
Hammerdchmidt and Kreye [25] proposed that the thermomechanical loading at the interface leads to the formation of a thin molten layer. The rapid cooling of the formed film would explain the fine grain size in this zone. Other research $[17,24]$ explains this zone is due to fine recrystallization at the interface, due to solid-state nature of explosive welding process.

The second zone (ZE2) (Figure 6c) contains grains that are less deformed than the grains of ZE1 and their boundary remains visible. The fundamental microscopic mechanism governing the plastic deformation of the grains in the co-based superalloy is the displacement of dislocations [22]. Under the action of the stresses generated in the superalloy by the cladding process, displacement proceeds according to a basic mechanism, namely crystallographic slip. This mechanism proceeds in multiple planes in the case of polycrystalline materials such as in the case of cobalt-based superalloys. Observations by Scanning Electron Microscope show that one or more slip systems are activated. Figure 7a shows some grains, in ZE2 (cross section), where only one slip system is present, shown by the trace of slip planes. Figure $7 \mathrm{~b}$ shows two transition bands showing a change in orientation within an individual grain of cobased superalloy. Figure $7 \mathrm{~b}$ and $7 \mathrm{c}$ also show a grain microstructure which is strongly aligned and broken down into several cells. The angles formed between the various slip lines observed within the grains with several slip systems are $\alpha=90^{\circ}, \beta=68^{\circ}$ and $\gamma=55^{\circ}$ (Figure $5 b)$. In this study, the superalloy has a fcc structure; in the case of materials with fcc structure, the principal slip systems are of the type $<110>\{111\}[23]$.

\subsection{XRD and EDS analysis:}

Figure 8(a) shows the diffractogram for the rolled cobalt-based superalloy before cladding. The five characteristic peaks of face centred cubic (f.c.c) cobalt are present. The hierarchy of the peaks in the diagram does not match that stated in the literature [21]. The intensity of the peak corresponding to plane (222) is greater than that of the peak corresponding to plane (200). This difference is due to the texture induced by the rolling of the superalloy sheet. 
The diffractograms for the top surface and for the interface of the cobalt-based superalloy isolated after explosion cladding are shown in figure 8(b) and 8(c) respectively. The two diffractograms show that the superalloy retains a f.c.c crystallographic structure, without sharp structure. All the cobalt peaks are present. The difference between the diffractograms can be due to:

- A reorientation of the grains due to the deformation involved by the explosive process and particularly at the interface during wave formation. This can explain the evolution of the amplitude ratios of the several peaks. Furthermore, the presence of the thin layer in ZE1 (figure 6c) can explain that the texture at the interface is less sharp.

- A difference of plastic deformation along the surface and the interface in the cobalt coating. Diffractometer measures on an area of dimension $(1 \mathrm{~mm} \times 1 \mathrm{~mm})$, this corresponding to the wavy interface period. Figure 8c shows the average diffractogram of a heterogeneous zone. This explains the observed texture evolution.

The calculated lattice parameter shows a major difference relative to the lattice parameter value for fcc cobalt stated in the literature $(\mathrm{a}=3.5447 \AA)$ [21]. For the rolled cobalt-based superalloy, the lattice parameter is of the order of $3.5826 \AA$; this value is $3.5810 \AA$ at the surface and at the interface of the superalloy isolated after cladding.

The chemical composition of HOLMZ1 and HELMZ2 is analysed by linear scanning perpendicular to the interface. The concentration profiles for HOLMZ1 (Figure 9) may be broken down into three parts. The first part is related to the chemical composition of $\mathrm{X} 38 \mathrm{CrMoV} 5$ steel. The second corresponds to the fine and homogeneous local fusion zone (HOLMZ1). The third part exhibits the chemical composition of the cobalt-based superalloy. Figure 10 shows the variation in concentration of the alloying elements in HELMZ2 and in the cobalt-based superalloy. The part of the profiles corresponding to HELMZ2 exhibits fluctuations in the concentration of the alloying elements (Figure 8). EDS analysis shows that 
HELMZ2 and HOLMZ1 have a chemical composition close to that of the superalloy. HELMZ2 exhibits a heterogeneous concentration. The evolution of the concentration of iron and cobalt, taking into account the diameter of the EDS measured zone, HELMZ2 appears as a mixture of melting of the two materials and superplastic deformed superalloy.

\subsection{Hardness and indentation test:}

In this study, the hardness of the cladded coating is measured with a durometer using a Vickers indenter under a load of $1 \mathrm{~kg}$. Figure $11 \mathrm{a}$ shows the hardness profile $\left(\mathrm{HV} \perp_{1 \mathrm{~kg}}\right)$ perpendicular to the interface. Hardness is uniform in the $\mathrm{X} 38 \mathrm{CrMoV} 5$ steel used as the base and remains close to that of the base before cladding, being of the order of $270 \mathrm{HV}^{\perp} \mathrm{kg}_{\text {. In }}$ the superalloy, hardness after cladding is relatively constant, of the order of $500 \mathrm{HV}_{1 \mathrm{~kg}}$, and is almost twice the hardness of the superalloy before cladding. Close to the interface, the superalloy exhibits a hardness peak that is of the order of $600 \mathrm{HV} \perp_{1 \mathrm{~kg}}$. This peak is due to the grain refining (see figure 6d) and work hardening in the zones (ZE1 and ZE2) close to the interface. The hardness profile $\left(\mathrm{HV}^{\prime \prime}{ }_{1 \mathrm{~kg}}\right)$ proceeded $4 \mathrm{~mm}$ deep from the top surface, (Figure 11b) shows that hardness on the superalloy side follows the wavy shape (Figure 6a). Its value varies between $300 \mathrm{HV}^{\prime \prime}{ }_{1 \mathrm{~kg}}$ and $450 \mathrm{HV}^{\prime \prime}{ }_{1 \mathrm{~kg}}$. The variation and increase in hardness of the superalloy after explosion cladding may be explained by the existence of two types of deformation. This is because, during the explosion cladding process, the sheet of superalloy is the focus for a first deformation throughout its thickness, which generates the initial dislocation phenomena. In the vicinity of the interface, the sheet undergoes a second plastic deformation associated with its application onto the steel and the shock wave generated by the collision. This second plastic deformation brings about an accumulation of dislocations, refining the structure, which increases the hardness of the superalloy in the vicinity of the interface. This phenomenon is accompanied by a multiplication of dislocations associated with the great extent and high speed of deformation. 
Figure 12 shows the impression at the interface under a load of $100 \mathrm{~kg}$. The impression is dissymmetric, being greatly deformed on the X38CrMoV5 steel side. The interface also deforms, but without any cracking along the diagonals of the impression. This shows that the interface between the cobalt-based superalloy and the X38CrMoV5 steel obtained by explosion cladding exhibits a good metallurgical and mechanical bond.

\section{Conclusions}

The results of these investigations may be summarised as follows:

- Cobalt-based superalloy sheets of a thickness of $5 \mathrm{~mm}$ can be explosive cladded onto base metal of X38CrMoV5 steel;

- The cobalt-based superalloy/X38CrMoV5 interface exhibits localised zones of fusion. This causes chemical heterogeneity at the interface. This does not appear to have any effect on the mechanical resistance of the interface;

- The interface does not exhibit any microcracking, being wave-like in appearance. Hardness in the superalloy is of the order of $500 \mathrm{HV}_{1 \mathrm{~kg}}$ with a peak of about 600 $\mathrm{HV}_{1 \mathrm{~kg}}$ located at the interface on the superalloy side.

- The f.c.c crystallographic structure of the cobalt does not change during the explosion cladding process. The microstructure of the superalloy at the interface is made up of greatly deformed grains with the appearance of slip lines.

- The interface exhibits a good metallurgical and mechanical bond.

\section{Acknowledgement}

This work is the fruit of a collaboration between CETIM (CEntre Technique de l'Industrie de la Mécanique) and ENSAM. Authors are obliged of the "Commission Forge Du CETIM" for its financial support. Authors also acknowledge the support of AFF (“Association Française de Forge"), DNC Nobelclad and ThyssenKruppVDM. 


\section{References}

[1] Q.Y.Hou, J.S.Gao,F.Zhou, Surface and Coatings Technology 194(2005)238.

[2] W.H. Jiang, H.R.Guan and Z.Q.Hu, Materials Science and Engineering A 27 (1999)101.

[3] A. Gatto, E. Bassoli, M. Fornari, Surface and Technology 187 (2004) 265.

[4] J.N.Aoh, J.C.Chen,Wear (2001) 611.

[5] S.Mridha, H.S.Ong,L.S.Poh and P.Cheang, Journal of Materials Processing Technology, $113(2001) \quad 516$.

[6] S. Buytoz, Surface and Coatings Technology 190 (2005) 212.

[7] D. Zhang, X. Zhang, Surface and Technology 187 (2004) 265.

[8]A.Zielinski, H. Smolenska,W. Serbinski, W. Konczewicz, A. Klimpel, Journal of Materials Processing Technology,164-165 (2005) 958

[9] L. Mingxi, H.Yizhu, S.Guoxing, Applied Surface Science 230 (2004) 201.

[10] Z.Tek, M.A. Gügör, E.Cal, M. Sonugelen, C. Artunç, A. Oztarhan, Surface and Coatings Technology 196 (2005) 317.

[11] R. Kaçar, M. Acarer, Materials Science and Engineering A 363 (2003) 290.

[12] L. Langlois, R. Bigot, O.Bomont, S.Ettaqi, and D.Bonin, $3^{\text {rd }}$ International Conference Integrated Design and Production, CPI'2003, Meknes, Morocco,13 , pp110-4,2003,Octobre $22,23, \& 24$

[13] R.C.Gupta, G.S.Kainth, Journal of Applied Mechanics, 57 (1990) 514.

[14] T. Izuma, K. Hokamoto, M. Fujita and T. Niwatsukino, Welding International 8 (8) (1994) 618.

[15] M. Acarer, B. Gülenç, F. Findik, Materials and Design 24 (2003) 659.

[16] K. Hokamoto, M. Fujita, H. Shimokawa, H. Okugawa, Journal of Material Processing Technology, 85 (1999) 175-179 
[17] Y.Li, H, Hashimoto, E. Sukedai, Y. Zhang and Z. Zhang, Journal of Electron Microscopy 49 (1) (2005) 5.

[18] L.E. Murr, C.S.Niou, E.P.Garcia, E. T. Ferreyra, J.M.Rivas, J.C.Sanchez, Materials Science and Engineering A 222 (1997) 118.

[19] U.K. Mudali, B.M.A. Rao, K. Shanmugam, R. Natarajan, B. Raj, Journal of Nuclear Materials 321 (2003) 40.

[20] R. Kaçar, M. Acarer, Journal of Materials Processing Technology 152 (2004) 91.

[21] National .Bureau of Standards. (U.S.) Monograph. 25410 (1966).

[22] J.A.Wert, Q.Liu and N.Hansen, Acta metal.mater.11(1995) 4153.

[23] X. Wu, N. Tao, Y. Hong, G. Liu, B. Xu, J. Lu, K. Lu, Acta Materialia 53 (2005) 681.

[24] A.A. Akbari Mousavi, S.T.S. Al-Hassani, Journal of the Mechanics and Physics of Solid, 53 (2005) 2501-2528

[25] M. Hammerschmidt, H. Kreye, Journal of Metals, 1984, 37(3), 12-21 


\section{Legends to illustrations}

Figure 1: Principle of explosive cladding process.

Table 1: Chemical composition of Conicro5010W and X38CrMoV5 (Wt\%).

Figure 2: Experimental details

Figure 3: Macrographs of the wavy morphology of the interface

a) after removal of the steel

b) Cross section

Figure 4: Optical micrographs of microstructure of Co-based superalloy before cladding

a) Microstructure under low magnification.

b) Microstructure under medium magnification.

c) Bands structures under high magnification.

Figure 5: Optical micrograph of the Co-based layer after explosive cladding

Figure 6: Microstructure at the interface of explosively cladded Co-based superalloy/ steel

a) General view of the interface between the Co-based superalloy (conirco5010W) coatings and the substrate (X38CrMoV5).

b) Microstructure of steel substrate close to the interface interface.

c) Microstructure of Co-based alloy Coating close to the interface.

d) Typical homogeneously local melting zones at the interface (HOLMZ1).

e) Typical heterogeneously local melting zones (HELMZ2) at the interface.

Figure 7: SEM micrographs of the microstructures of the cobalt-based superalloy layer after explosion cladding.

Figure 8: X-ray diffraction pattern of Co-based alloy coating

a) XRD patterns of Co-based superalloy before cladding

b) XRD patterns of top surface of Co-based alloy coating.

c) XRD patterns of bottom surface (interface) of Co-based alloy coating. 
Figure 9: Microstructures and composition profiles of HOLMZ1

Figure 10: Microstructures and composition profiles of HELMZ2

Figure 11: Vickers Hardness profiles

a) Hardness $\mathrm{HV}^{\perp} \perp_{1 \mathrm{~kg}}$ measured perpendicular to the interface.

b) Hardness variation $\left(\mathrm{HV}^{\prime \prime}{ }_{1 \mathrm{~kg}}\right)$ in Co-based superalloy coating $4 \mathrm{~mm}$ deep from the top surface.

Figure 12: Optical micrograph of hardness impression at the interface Co-based superalloy/ steel 